\title{
Atividade Relativa da Catalase de losna-Branca (Parthenium hysterophorus) COMPARAdA À DE OUTRAS EsPÉCIES DANINHAS ${ }^{1}$
}

\author{
Catalase Relative Activity of Ragweed (Parthenium hysterophorus) Compared to That of Other \\ Weed Species
}

\author{
CARVALHO, S.J.P. ${ }^{2}$, MACHADO, E.C.R. ${ }^{3}$, MARQUES, B.S. ${ }^{3}$, SILVA, A.P.P. ${ }^{3}$, LIMA, R.S.O. ${ }^{3}$ \\ e COSTA, R. ${ }^{3}$
}

\begin{abstract}
RESUMO - Este trabalho foi desenvolvido com o objetivo de avaliar a atividade relativa da catalase em extrato aquoso de losna-branca (Parthenium hysterophorus), bem como comparála à atividade da catalase de outras espécies daninhas. O trabalho constou de três fases, que envolveram a padronização do método, comparação da atividade relativa da catalase de plantas da familia Asteraceae e comparação com outras 11 espécies daninhas, sendo estas: Euphorbia heterophylla, Alternantheratenella, Cenchrus echinatus, Panicum maximum, Amaranthus viridis, Ipomoea hederifolia, Galinsoga parviflora, Bidens pilosa, Sonchus oleraceus, Cyperus rotundus e Commelina benghalensis. Observou-se resposta linear crescente da reação entre extrato aquoso de losna-branca e peróxido de hidrogênio, em razão da concentração do extrato vegetal. Em todas as fases, a atividade relativa da catalase de extrato de losna-branca foi superior à atividade da catalase das demais espécies daninhas. Com os dados obtidos nas três fases, conclui-se que a maior atividade relativa observada para a catalase da losnabranca contribui significativamente para a tolerância dessa espécie ao herbicida paraquat. Essa maior atividade pode ser consequência da maior concentração enzimática nas células ou devido à maior atividade intrínseca da enzima (afinidade enzima-substrato), havendo necessidade de estudos mais precisos para essa conclusão.
\end{abstract}

Palavras-chave: Asteraceae, enzima, paraquat, peróxido de hidrogênio, tolerância.

\begin{abstract}
This work was carried out to evaluate catalase relative activity of ragweed (Parthenium hysterophorus) aqueous extract, as well as to compare it with catalase activity of other weed species. It consisted of three phases, involving method standardization, comparison of the catalase relative activity in Asteraceae family plants and that of ragweed catalase activity with the following 11 weed species: Euphorbia heterophylla, Alternanthera tenella, Cenchrus echinatus, Panicum maximum, Amaranthus viridis, Ipomoea hederifolia, Galinsoga parviflora, Bidens pilosa, Sonchus oleraceus, Cyperus rotundus and Commelina benghalensis. Reaction of ragweed aqueous extract with hydrogen peroxide had increasing linear response regarding plant extract concentration. In all phases, catalase relative activity of ragweed extract was superior to catalase activity of the other weed species. Data obtained in these phases allowed to conclude that higher relative activity observed for ragweed catalase significantly contributes to the tolerance of this species to paraquat. This higher activity might be due to higher enzymatic concentration in ragweed cells or to higher intrinsic enzymatic activity (enzyme-substrate affinity).Therefore, further studies are necessary to support this conclusion.
\end{abstract}

Keywords: Asteraceae, enzyme, paraquat, hydrogen peroxide, tolerance

Recebido para publicação em 2.7.2011 e aprovado em 3.3.2012.

2 Engo-Agr ${ }^{\circ}$, Doutor em Fitotecnia, Professor do Instituto Federal de Educação, Ciência e Tecnologia do Sul de Minas Gerais IFSULDEMINAS, Caixa Postal 1004, 37750-971 Campus Machado, <sjpcarvalho@yahoo.com.br>; ${ }^{3}$ Graduandos em Engenharia Agronômica, IFSULDEMINAS, Campus Machado. 


\section{INTRODUÇÃO}

A losna-branca (Parthenium hysterophorus) é uma espécie nativa do continente americano, originária do nordeste do México, que foi introduzida acidentalmente em diversos países, como Índia, Austrália, EUA, China, Paquistão e Brasil. Essa planta pode infestar lavouras e pastagens, interferir nas práticas agrícolas, promover intoxicação do gado, causar interferência alelopática em algumas culturas, além de ser reservatório natural de pragas e doenças de importância para a agricultura (Lucchini et al., 2005). Dessa forma, com frequência, herbicidas são utilizados para eliminação dessa planta daninha, havendo, inclusive, relatos da resistência de losna-branca aos inibidores da ALS (Gazziero et al., 2006).

Entre os diversos herbicidas registrados no Brasil, pode-se destacar o paraquat. Tratase de um produto não seletivo, com ação de contato, recomendado para dessecações e/ou aplicações dirigidas às entrelinhas de diversas culturas. Nas plantas, o paraquat atua capturando os elétrons provenientes do fotossistema I, com posterior formação de radicais livres, os quais são rapidamente oxidados a superóxidos; posteriormente, por dismutação, temse a formação de peróxido de hidrogênio (água oxigenada), que possui elevada ação tóxica em nivel celular (Silva et al., 2007). No entanto, são encontrados alguns relatos sobre a tolerância de certas espécies a esse herbicida, em especial da losna-branca (Njoroge, 1991; Nicolai et al., 2004; Martins et al., 2008).

Segundo Christoffoleti \& López-Ovejero (2008), a tolerância de plantas daninhas a herbicidas é uma característica inata que a espécie possui em sobreviver a aplicações de herbicidas, na dose recomendada, que seriam letais a outras espécies, sem alterações marcantes em seu crescimento e desenvolvimento. É uma característica que existe na planta antes mesmo da primeira aplicação do herbicida em determinada área.

Há diversas explicações para a tolerância de plantas daninhas a herbicidas, entre elas a presença de enzimas que rapidamente eliminam agentes oxidativos da célula, com destaque para a superóxido dismutase, a ascorbato peroxidase e a catalase (Chelikani et al., 2004;
Martins et al., 2008). As catalases são um grupo de enzimas que promove a degradação de duas moléculas de peróxido de hidrogênio (água oxigenada) em água e oxigênio (Chelikani et al., 2004; Tabaldi et al., 2007). Assim, maiores concentrações de catalase nas células, ou mesmo maior atividade dessa enzima, podem ser explicações para a tolerância da losna-branca ao herbicida paraquat.

Este trabalho foi desenvolvido com o objetivo de avaliar a atividade relativa da catalase em extrato aquoso de losna-branca (Parthenium hysterophorus), bem como compará-la à atividade da catalase de outras espécies daninhas (Galinsoga parviflora, Euphorbia heterophylla, Alternanthera tenella, Cenchrus echinatus, Panicum maximum, Amaranthus viridis, Ipomoea hederifolia, Galinsoga parviflora, Bidens pilosa, Sonchus oleraceus, Cyperus rotundus e Commelina benghalensis).

\section{MATERIAL E MÉTODOS}

Este trabalho foi desenvolvido no Laboratório de Análise de Alimentos do Instituto Federal de Educação, Ciência e Tecnologia do Sul de Minas Gerais, campus Machado, entre março e abril de 2011. Todo o trabalho contou com três fases. Em todas as fases, avaliou-se a reação de extratos aquosos vegetais (presença da enzima catalase) com peróxido de hidrogênio (água oxigenada, 10 volumes), por meio do método prático. Todos os extratos aquosos vegetais foram preparados a partir da trituração de limbos foliares de plantas adultas, em florescimento, coletandose material em posições aleatórias do dossel. Os limbos foliares foram coletados em áreas agrícolas do campus ou em áreas não agrícolas do municipio de Machado-MG e imediatamente transportados até o laboratório. Eles foram processados em liquidificador por dois minutos, utilizando água deionizada como veículo. Posteriormente, retiraram-se as partículas maiores remanescentes, com uso de coador comum.

O método prático está fundamentado na mensuração da reação ocorrida dentro de seringas plásticas, promovendo-se a sucção do extrato aquoso vegetal e, em seguida, do peróxido de hidrogênio. Imediatamente após a entrada do peróxido de hidrogênio na seringa, 
tampa-se esta, promove-se agitação (cinco inversões) e observa-se o deslocamento espontâneo do êmbolo, devido ao desprendimento de oxigênio. Após tempo predeterminado, anota-se o valor indicado pelo êmbolo. Considera-se o volume de $\mathrm{O}_{2}$ produzido como a diferença entre a medida final do êmbolo e o volume inicial de líquido (extrato vegetal e peróxido de hidrogênio). Em todos os casos, procedeu-se à sucção inicial de $5 \mathrm{~mL}$ de extrato aquoso vegetal e $5 \mathrm{~mL}$ de peróxido de hidrogênio.

\section{Primeira fase: triagem e padronização do método}

A primeira fase foi desenvolvida com os objetivos de calibrar o método prático de quantificação da atividade relativa da catalase e caracterizar o comportamento-padrão do extrato aquoso de losna-branca. Foram avaliados diferentes períodos de reação, tamanho das seringas e concentrações dos extratos (gramas de limbo por litro de água deionizada). A padronização final da reação entre extrato aquoso de losna-branca e peróxido de hidrogênio foi obtida por meio de experimento com delineamento em blocos ao acaso, com quatro tratamentos (concentrações do extrato: 40, 30, 20 e $\left.10 \mathrm{~g} \mathrm{~L}^{-1}\right)$ e oito repetições.

O tempo de reação foi padronizado em um minuto, exceto para a concentração de $10 \mathrm{~g} \mathrm{~L}^{-1}$, em que se aguardaram dois minutos. Posteriormente, realizou-se compensação do volume de gás, dividindo-se o volume obtido por dois. A temperatura média do ambiente foi de $23,3{ }^{\circ} \mathrm{C}$. Foram utilizadas seringas de $50 \mathrm{~mL}$ (concentrações de 40, 30 e $20 \mathrm{~g} \mathrm{~L}^{-1}$ ) e $20 \mathrm{~mL}$ (concentração de $10 \mathrm{~g} \mathrm{~L}^{-1}$ ).

\section{Segunda fase: comparação na família} Asteraceae

Um experimento foi desenvolvido com o objetivo de comparar a atividade relativa da catalase de extrato aquoso de losna-branca com duas outras espécies daninhas da familia Asteraceae, sendo estas: falsa-serralha (Emilia sonchifolia) e picão-branco (Galinsoga parviflora). Foi utilizado esquema de tratamentos fatorial $3 \times 4$, em que três foram as espécies daninhas e quatro foram as concentrações do extrato $\left(40,30,20\right.$ e $\left.10 \mathrm{~g} \mathrm{~L}^{-1}\right)$, com oito repetições. Também nesse caso o tempo de reação foi padronizado em um minuto, exceto para a concentração de $10 \mathrm{~g} \mathrm{~L}^{-1}$, em que se aguardaram dois minutos. Posteriormente, realizou-se compensação do volume de gás, dividindo-se o volume obtido por dois. A temperatura média do ambiente foi de $22{ }^{\circ} \mathrm{C}$. Foram utilizadas seringas de $50 \mathrm{~mL}$ (concentrações de 40, 30 e $20 \mathrm{~g} \mathrm{~L}^{-1}$ ) e $20 \mathrm{~mL}$ (concentração de $10 \mathrm{~g} \mathrm{~L}^{-1}$ ).

Terceira fase: comparação entre 12 espécies daninhas

Um experimento foi desenvolvido com o objetivo de comparar a atividade relativa da catalase de extrato aquoso de losna-branca com a de outras 11 espécies de plantas daninhas: amendoim-bravo (Euphorbia heterophylla), apaga-fogo (Alternanthera tenella), capimcarrapicho (Cenchrus echinatus), capimcolonião (Panicum maximum), caruru-demancha (Amaranthus viridis), corda-de-viola (Ipomoea hederifolia), picão-branco (Galinsoga parviflora), picão-preto (Bidens pilosa), serralha (Sonchus oleraceus), tiririca (Cyperus rotundus) e trapoeraba (Commelina benghalensis).

Foi utilizado delineamento experimental de blocos ao acaso, com 12 tratamentos (espécies) e oito repetições. Nesta fase, o tempo de reação foi padronizado em um minuto, todos os extratos vegetais tiveram concentrações de $40 \mathrm{~g} \mathrm{~L}^{-1}$ e utilizaram-se seringas de $50 \mathrm{~mL}$ para as medições. A temperatura média do ambiente foi de $21,2{ }^{\circ} \mathrm{C}$.

\section{Análise estatistica}

Em todas as fases, aplicou-se o teste $\mathrm{F}$ na análise da variância, seguido de regressões polinomiais (concentrações de extratos aquosos) ou do teste de Tukey (comparação das espécies). Todos os testes foram utilizados com nivel de significância de $5 \%$.

\section{RESULTADOS E DISCUSSÃO}

Na primeira fase dos testes, observou-se resposta linear crescente da reação entre extrato aquoso de losna-branca e peróxido de hidrogênio, em razão da concentração do extrato, com deslocamento máximo do êmbolo (volume de $\mathrm{O}_{2}$ ) superior a $30 \mathrm{~mL}$ (Figura 1). Dessa forma, comprova-se a viabilidade do método prático em estimar a atividade 


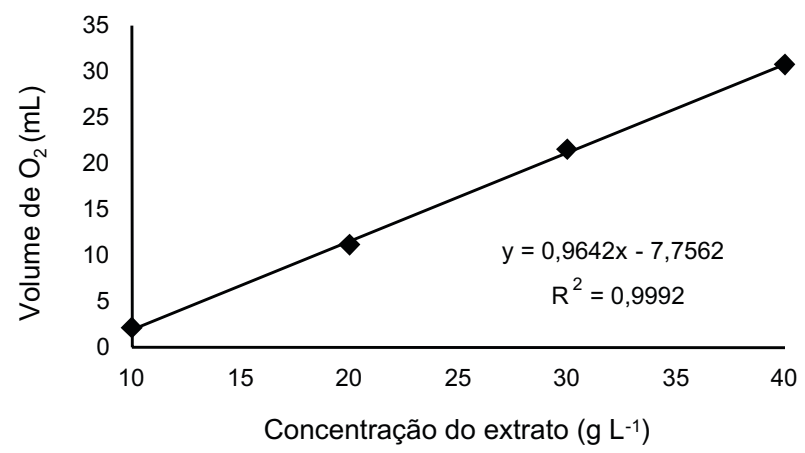

Figura 1 - Volume deslocado no interior da seringa $\left(\mathrm{O}_{2}\right)$ após reação entre $5 \mathrm{~mL}$ de extrato aquoso de losna-branca (Parthenium hysterophorus) e $5 \mathrm{~mL}$ de peróxido de hidrogênio, para diferentes concentrações de extrato. Machado-MG, 2011.

relativa da catalase em extratos aquosos vegetais. Martins et al. (2008) também avaliaram a atividade da catalase em plantas de losna-branca, porém com auxílio de espectrofotômetro. Observaram incremento da atividade enzimática após pulverização das plantas com o herbicida paraquat, concluindo que a atividade de enzimas antioxidantes em losna-branca, sobretudo a superóxido dismutase e a catalase, pode estar relacionada com a tolerância da espécie ao paraquat.

As catalases - ou mais corretamente hidroperoxidases - são uma das classes de enzimas mais extensamente estudadas e que não seguem a cinética proposta por MichaelisMenten, exceto para concentrações muito baixas do substrato (Chelikani et al., 2004). Adicionalmente, as catalases não dependem de outros agentes redutores para eliminação de $\mathrm{H}_{2} \mathrm{O}_{2}$, o que representa a maior vantagem desta enzima (Feierabend, 2005).

Na segunda fase, comparou-se a atividade relativa da catalase de losna-branca com a do picão-branco e a da falsa-serralha, ambas espécies da família Asteraceae. Detectou-se maior atividade enzimática no extrato aquoso de losna (Figura 2), corroborando os dados obtidos na primeira fase, que justificam maior tolerância desta espécie ao paraquat. Neste caso, o método prático não foi adequado para quantificar a atividade da enzima na menor concentração do extrato $\left(10 \mathrm{~g} \mathrm{~L}^{-1}\right)$ para as espécies mais sensiveis ao herbicida, de modo que esses dados foram descartados. Em geral, a atividade relativa detectada para a catalase foi semelhante entre o picão-branco e a falsaserralha (Figura 2).

Em experimentos de campo, Nicolai et al. (2004) constataram falha de controle de losnabranca após pulverização de paraquat em área de café. De forma semelhante, Njoroje (1991) confirmou tolerância de losna-branca ao herbicida paraquat em cafezais do Quênia. Rodrigues \& Almeida (2005) não indicam uso de paraquat para controle de losna-branca; e Lorenzi (2006), por sua vez, classifica indivíduos adultos de losna-branca como pouco suscetiveis ao paraquat.

Na terceira fase, foram obtidos resultados significativos que evidenciaram maior atividade relativa enzimática da catalase em extrato de losna-branca, superior à de todas as demais espécies daninhas testadas (Tabela 1). $\mathrm{O}$ amendoim-bravo e o caruru-de-mancha também tiveram significativa produção de $\mathrm{O}_{2}$, porém inferior à do extrato de losna-branca. Vale ressaltar a baixíssima atividade da catalase observada nos extratos de plantas das famílias Poaceae (capim-colonião e capimcarrapicho) e Cyperaceae (Tabela 1). Considerando o trabalho em geral, a losna-branca foi testada nas três fases, obtendo-se resultados bastante semelhantes e consistentes, o que auxilia na validação científica do método.

No tocante às enzimas, Chelikani et al. (2004) comentam sobre a existência de três classes de proteínas não relacionadas em sua sequência de aminoácidos (mais de 200 sequências) e estrutura que exibem

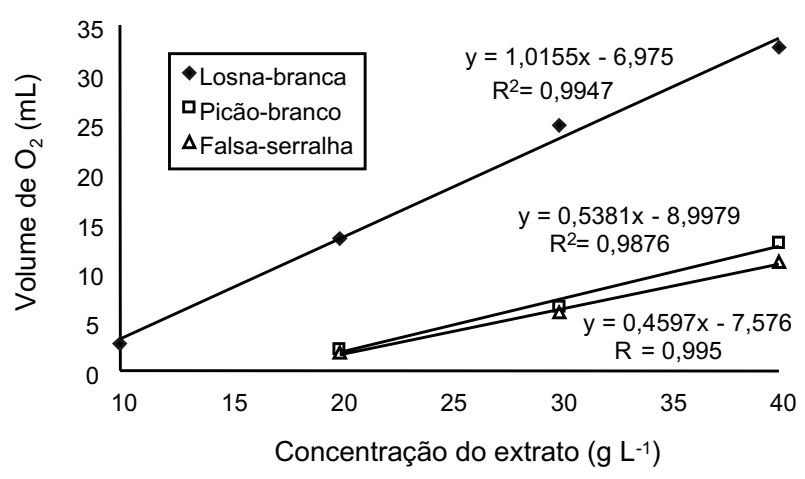

Figura 2 - Volume deslocado no interior da seringa $\left(\mathrm{O}_{2}\right)$ após reação entre $5 \mathrm{~mL}$ de peróxido de hidrogênio e $5 \mathrm{~mL}$ de extrato aquoso de losna-branca (Parthenium hysterophorus), picão-branco (Galinsoga parviflora) e falsa-serralha (Emilia sonchifolia). $\mathrm{DMS}_{\mathrm{Esp}}=1,38$. Machado-MG, 2011. 
Tabela 1 - Volume deslocado no interior da seringa $\left(\mathrm{O}_{2}\right)$ após reação entre $5 \mathrm{~mL}$ de peróxido de hidrogênio e $5 \mathrm{~mL}$ de extrato aquoso (40 $\left.\mathrm{g} \mathrm{L}^{-1}\right)$ de 12 espécies de plantas daninhas ${ }^{1 /}$. Machado-MG, 2011

\begin{tabular}{|l|l|c|}
\hline \multicolumn{2}{|c|}{ Espécie de planta daninha } & \multirow{2}{*}{$\begin{array}{c}\text { Volume de } \mathrm{O}_{2} \\
(\mathrm{~mL})\end{array}$} \\
\hline Nome comum & Nome científico & $34,3 \mathrm{a}$ \\
\hline Losna-branca & Parthenium hysterophorus & $26,4 \mathrm{~b}$ \\
\hline Caruru-de-mancha & Euphorbia heterophylla & $23,5 \mathrm{bc}$ \\
\hline Trapoeraba & Amaranthus viridis & $21,1 \mathrm{c}$ \\
\hline Serralha-verdadeira & Commelina benghalensis & $20,9 \mathrm{c}$ \\
\hline Apaga-fogo & Sonchus oleraceus & $17,2 \mathrm{~d}$ \\
\hline Corda-de-viola & Alternanthera tenella & $15,9 \mathrm{~d}$ \\
\hline Picão-branco & Ipomoea hederifolia & $14,8 \mathrm{~d}$ \\
\hline Picão-preto & Galinsoga parviflora & $9,6 \mathrm{e}$ \\
\hline Capim-colonião & Bidens pilosa & $1,9 \mathrm{f}$ \\
\hline Tiririca & Panicum maximum & $1,1 \mathrm{f}$ \\
\hline Capim-carrapicho & Cyperus rotundus & $0,0 \mathrm{f}$ \\
\hline F $=274,86 * *$ & Cenchrus echinatus & $\mathrm{DMS}=3,1$ \\
\hline
\end{tabular}

** Teste $\mathrm{F}$ significativo a $1 \%$ de probabilidade; ${ }^{1 /}$ Médias seguidas por letras iguais, na coluna, não diferem entre si pelo teste de Tukey a $5 \%$ de probabilidade.

significativa atividade como catalases, com elevada divergência em suas propriedades e eficiência. Segundo Azevedo et al. (1998), mais de uma isoenzima de catalase é normalmente observada em espécies vegetais. Assim, com os dados obtidos nas três fases, conclui-se que a maior atividade relativa da catalase da losna-branca contribui significativamente para a tolerância desta espécie ao herbicida paraquat. Essa maior atividade pode ser consequência da maior concentração enzimática nas células ou devido à maior atividade intrínseca da enzima (afinidade enzima-substrato), havendo necessidade de estudos mais precisos para essa conclusão.

\section{LITERATURA CITADA}

AZEVEDO, R. A. et al. Response of antioxidant enzymes to transfer from elevated carbon dioxide to air and ozone fumigation, in the leaves and roots of wild-type and a catalase-deficient mutant of barley. Physiol. Plant., v. 104, n. 2, p. 280-292, 1998.

CHELIKANI, P.; FITA, I.; LOEWEN, P. C. Diversity of structures and properties among catalases. Cellular Molec. Life Sci., v. 61, n. 1, p. 192-208, 2004.

CHRISTOFFOLETI, P. J.; LÓPEZ-OVEJERO, R. F.

Resistência de plantas daninhas a herbicidas: definições, bases e situação no Brasil e no mundo. In: CHRISTOFFOLETI, P. J. (Coord.) Aspectos de resistência de plantas daninhas a herbicidas. Piracicaba: HRAC-BR, 2008. p. 3-30.
FEIERABEND, J. Catalases in plants: molecular and functional properties and role in stress defense. In: SMIRNOFF, N. (Ed.). Antioxidants and reactive oxygen species in plants. Oxford: Blackwell, 2005. p. 101-140.

GAZZIERO, D. L. P.; BRIGHENTI, A. M.; VOLL, E. Resistência cruzada da losna-branca (Parthenium hysterophorus) aos herbicidas inibidores da enzima acetolactato sintase. Planta Daninha, v. 24, n. 1, p. 157-162, 2006.

LORENZI, H. Manual de identificação e controle de plantas daninhas: plantio direto e convencional. 6.ed. Nova Odessa: Instituto Plantarum, 2006. 339 p.

LUCCHINI, F. et al. A losna-branca Parthenium hysterophorus L. (Heliantheae: Asteraceae), planta invasora exótica do Brasil. Jaguariúna: Embrapa, 2005. 5 p. (Comunicado Técnico, 29)

MARTINS, B. A. B. et al. Effect of the herbicide paraquat on superoxide dismutase (SOD) and catalase (CAT), in Parthenium hysterophorus (ragweed). In: CONGRESO DE LA ASOCIACIÓN LATIONAMERICANA DE MALEZAS, 18., Ouro Preto, 2008. A ciência das plantas daninhas na sustentabilidade dos sistemas agrícolas. Sete Lagoas: SBCPD/Embrapa Milho e Sorgo, 2008. 9 p. CD-ROM.

NICOLAI, M. et al. Gramocil (paraquat + diuron) como alternativa ao uso de glyphosate no controle de plantas daninhas em café: dose cheia e sequencial. In: CONGRESSO BRASILEIRO DA CIÊNCIA DAS PLANTAS DANINHAS, 24., 2004, São Pedro. Suplemento... São Pedro: SBCPD, 2004. p. 265. 
NJOROGE, J. M. Tolerance of Bidens pilosa L. and Parthenium hysterophorus L. to paraquat (Gramoxone) in Kenya coffee. Kenya Coffee, v. 56, n. 651, p. 999-1001, 1991.

RODRIGUES, B. N.; ALMEIDA, F. S. Guia de herbicidas. 5.ed. Londrina: 2005. 592 p.
SILVA, A.A.; FERREIRA, F.A.; FERREIRA, L.R. Herbicidas: classificação e mecanismo de ação. In: SLVA, A. A.; SILVA, J. F. (Eds.). Tópicos em manejo de plantas daninhas. Viçosa, MG: Universidade Federal de Viçosa, 2007. p. 83-148.

TABALDI, L. A. et al. Physiological and oxidative stress responses of four potato clones to aluminum in nutrient solution Braz. J. Plant Physiol., v. 19, n. 3, p. 211-222, 2007 